\title{
COVID-19 and its impact on Peruvian dentistry
}

\section{El impacto del COVID-19 en la odontología peruana}

Angela Quispe-Salcedo ${ }^{1(1)}$ aquispesa@cientifica.edu.pe

Artículo recibido: $23 / 03 / 2020$ Artículo aceptado: 06/04/2020

Citar como: Quispe-Salcedo A. COVID-19 and its impact on Peruvian dentistry. Rev Cient Odontol (Lima). 2020; 8(1): e001. DOI: $10.21142 / 2523-2754-0801-2020-001$
The arrival of the SARS-CoV-2 virus to our country has signified a major event in our recent history. The COVID-19 pandemic started in December 2019 in the city of Wuhan, China, and since then, has spread to almost every country in the world. Although the mortality rate is low (less than $5 \%$ of positive cases), patients who develop the disease may present a severe acute respiratory syndrome, which implies urgent hospitalization, and in the worst case scenario, the assistance of a mechanical ventilator $\left({ }^{1}\right)$.

Knowing the dramatic situation of the health system in our country, on March $16^{\text {th }}$ the government applied strict measures to control the spread of infection and gain time to strengthen the capacity of medical assistance, as well as reinforce the protocols of testing and diagnosis. These regulations included enforced quarantine in the whole country with transit restrictions for two weeks. Later, the government announced a strict curfew from $8 \mathrm{pm}$ to $5 \mathrm{am}$ and extension of the quarantine period for an additional 13 days. Although very necessary, these measures implied the temporary closure of educational institutions at all levels, and several non-essential businesses, including dental clinics and related services.

According to a recent publication $\left(^{2}\right)$, dentists are considered the occupational group with the highest risk of contagion for COVID-19. Since the virus is transmitted from person to person, the treatment of COVID-19 - positive patients represents a source of contagion and transmission. The aerosol generated during dental procedures can directly contaminate health care personnel and adjacent surfaces, on which it has been shown that the virus can survive for several hours without adequate cleaning $\left({ }^{3}\right)$. At present, the Ministry of Health is allowing the treatment of dental emergencies, while other dental activities, including even non-invasive procedures, have been suspended.

Only a small percentage of dentists in Peru have a stable, permanent position, either in public health or educational institutions. Most of our colleagues earn a living by daily work contracted by dental clinics under a payment system based on the percentage of production, or from the income generated by independent private practice. Considering that protection measures against the disease will not be lifted in their entirety at the end of this exceptional period of quarantine,

\footnotetext{
1 Carrera de Estomatología, Universidad Científica del Sur. Lima, Perú.
} 
it remains unknown what will happen to the thousands of dental surgeons and their private practices in our country. The reality ahead will be difficult for everyone. It is likely that the restriction of dental care limited to emergencies will be maintained; however, independent dental surgeons will not survive under this scheme. In this context, it is necessary for our National Dental Board to intercede to obtain protective measures or economic stimuli for dentists. In addition, the Board must press for the implementation of contingency funds for the members of our dental community who need it most in greatest need.

It is also important to establish a technical committee to direct the elaboration of policies and guidelines for dental services guaranteeing the safety of both the patients and all the members of the dental team. All this effort should be made according to the recommendations for primary health care promoted by the Ministry of Health, taking into consideration the participation of other health sciences specialties. Moreover, these protocols should be published soon, in order for their implementation and compliance in the public and private sectors to be supervised by the regional dental boards in the weeks

\section{REFERENCIAS BIBLIOGRÁFICAS}

1. Yuki K, Fujiogi M, Koutsogiannaki S. COVID-19 pathophysiology: A review [published online ahead of print]. Clin Immunol. 2020; 108427. doi: 10.1016/j.clim.2020.108427

2. Meng L, Hua F, Bian Z. Coronavirus disease 2019 (COVID-19): emerging and future challenges for dental and oral medicine. J Dent Res. 2020; 99 (5): 481-7. doi: 10.1177/0022034520914246

3. Van Doremalen N, Bushmaker T, Morris DH, et al. Aerosol and surface stability of SARS-CoV-2 as compared with SARSCoV-1. N Engl J Med. 2020; 382 (16): 1564-7. doi: 10.1056/ NEJMc2004973 after the end of the period of social immobilization, in the absence of further complementary measures.

On the other hand, the impact of the COVID-19 pandemic will undoubtedly affect the education of dental students at the undergraduate and postgraduate levels throughout the country. The maintenance of social distancing limiting the number of students per room, the restriction of rotations in hospitals, and the decrease in the number of patients in the dental teaching clinics are just a few examples of the obstacles which must be overcome in the next months $\left({ }^{4}\right)$. Given the sensitivity of this matter, the criteria of dental education in times of COVID-19 should be carefully addressed in another publication.

As health professionals, we need to support each other amid this pandemic. Even though we are not at the front line, we must remain ready and willing to participate with any other initiative that can benefits the population in the midst of this difficult situation $\left(^{5}\right)$. Let's do as much as we can to support those in our community in most need and set an example by fully complying with government measures. Keep in mind that finally, all the good we can do, always comes back.

4. Iyer P, Aziz K, Ojcius DM. Impact of COVID-19 on dental education in the United States [published online ahead of print]. J Dent Educ. 2020; 10.1002/jdd.12163. doi: 10.1002/jdd.12163

5. Coulthard P. Dentistry and coronavirus (COVID-19) - moral decision-making. Br Dent J 2020; 228 (7): 503-5. doi: 10.1038/ s41415-020-1482-1 